\section{Situating Second-Year Success: Understanding Second-Year STEM Experiences at a Liberal Arts College}

\author{
Leslie Gregg-Jolly, ${ }^{* *}$ Jim Swartz," Ellen Iverson, \\ and David Lopatto" \\ 'Department of Biology, "Department of Chemistry, "Office of the Dean, "Center for Teaching, \\ Learning, and Assessment, and "Department of Psychology, Grinnell College, Grinnell, IA 50112; \\ §Science Education Resource Center, Carleton College, Northfield, MN 55057
}

\begin{abstract}
Challenges particular to second-year students have been identified that can impact persistence in science, technology, engineering, and mathematics (STEM) fields. We implemented a program to improve student success in intermediate-level science courses by helping students to feel they belonged and could succeed in STEM. We used survey measures of perceptions and attitudes and then qualitative measures to characterize the impact of support strategies, including peer mentoring, a second-year science student retreat, learning and advising support resources, and department-specific activities. Analysis of registration and transcript information revealed underperformance by students of color (SOC) and first-generation (FG) students in 200-level science courses. Comparison of these data before and during programming revealed significant improvement in success rates of these students in 200-level biology and chemistry courses, but success rates of SOC and FG students remain lower than the overall rate for 200-level science courses. Contemporaneous with the program, qualitative and quantitative measures of student attitudes revealed a high level of belongingness and support. The results suggest that a focus on students' metacognition about their own abilities and strategic knowledge of how to succeed may be a fruitful direction for future research.
\end{abstract}

\section{INTRODUCTION}

National efforts to improve recruitment and persistence of students in the sciences have included curricular and pedagogical reforms designed to increase student engagement through active pedagogical practices and authentic research experiences. Other efforts focus on providing supportive programming to help students develop academic self-efficacy so they can identify themselves as being scientists and belonging to a scientific community (e.g., Jolly et al., 2004; Graham et al., 2013; Gross et al., 2015). There has been widespread reform in introductory science courses and programming, such as bridge programs, help centers, and mentoring programs to help beginning students succeed and maintain an interest in science, technology, engineering, and mathematics (STEM)-related fields. Although these efforts have led to some successful outcomes, as a whole they have not appeared to generate the desired increased diversity and numbers of STEM professionals nationally (Lopatto, 2010, and references therein). This indicates that reform efforts are needed to support students and professionals at many stages of education and training. Here, we report an example in which students of color (SOC, self-reported as black, Latina/o, Asian, Native American, and multiethnic) and first-generation (FG) students at Grinnell College experienced lower rates of success in intermediate-level science courses in an institutional backdrop of a mature program (the Grinnell Science Project) of support and reformed pedagogies for introductory-level students. We describe a comprehensive set
Pat Marsteller Monitoring Editor Submitted January 15, 2016; Revised April 29, 2016; Accepted June 15, 2016

CBE Life Sci Educ September 1, 2016 15:ar43 DOI:10.1187/cbe.16-01-0044

*Address correspondence to: Leslie Gregg-Jolly (greggjol@grinnell.edu).

(c) 2016 L. Gregg-Jolly et al. CBE-Life Sciences Education ๑ 2016 The American Society for Cell Biology. This article is distributed by The American Society for Cell Biology under license from the author(s). It is available to the public under an Attribution-Noncommercial-Share Alike 3.0 Unported Creative Commons License (http://creativecommons.org/licenses/ by-nc-sa/3.0).

"ASCB®" and "The American Society for Cell Biology $\rrbracket^{\prime \prime}$ are registered trademarks of The American Society for Cell Biology. 
of interventions designed to promote inclusive success of second-year Grinnell students and how we have used data to identify the problem, inform intervention programming, and monitor progress toward achieving a goal of supporting the progress of all science students.

\section{Challenges Particular to Second-Year Students May Impact Persistence in STEM Fields}

A significant body of research published in the past 20 years confirms that the second year of college is one of significant transition for students, involving both developmental and environmental factors (Schreiner and Pattengale, 2000; Tobolowsky and Cox 2007a; Hunter et al., 2010). There are specific developmental concerns in the second year of college, including both random and focused exploration (Schaller, 2005) and developing a sense of purpose (Lemons and Richmond, 1987; Gansemer-Topf et al., 2007; Young et al., 2015). During this time, students are asking big questions and feeling the weight of making significant life and career decisions. These stages have to do with both personal relationships and academic choices.

The notion of a sophomore slump defined in various ways has been studied for decades (Freedman, 1956; Lemons and Richmond, 1987; Wilder, 1993; Gardner, 2000; Schreiner and Pattengale, 2000; Kennedy and Upcraft, 2010). Based on a recent comprehensive review of studies involving second-year students, Kennedy and Upcraft (2010) redefine the sophomore slump as including one or more of the following features: academic deficiencies, academic disengagement, dissatisfaction with the collegiate experience, major and career indecision, and developmental confusion. Slumping does happen with some students, but how often? In a large national study of college sophomores across 24 different institutions-the Sophomore Experiences Survey-Young et al. (2015) discovered that $\sim 20 \%$ of students, by Kennedy and Upcraft's definition, are "slumping," and many others are not thriving.

Research conducted at Grinnell College (Gansemer-Topf et al., 2007) emphasized that environmental features significantly impact second-year students. The second year of college brings significant changes and challenges for students across various dimensions: academic, social, and extracurricular. Within the academic area, students adjust to more rigorous course work and changing advisors as they move from having general liberal arts advisors to advisors in their major disciplines. Second-year students are also doing considerable academic planning to fulfill college expectations of declaring a major, deciding whether to participate in off-campus study, and so on. They have to manage nervousness about making irrevocable decisions in constructing an academic plan that inevitably forecloses other opportunities, and they wrestle with the increased responsibility they have for dealing with the consequences of choices they have made in defining their direction and the identity shift that comes with this. As they experience more academically challenging course work in their intended major-through which they often form new social connections or deepen existing ones - they also encounter increased rigor in their studies. At the same time, they feel busier managing social relationships and increased involvement in leadership positions on campus. When students struggle or falter with those new academic demands, some question whether or not they belong in that academic environment (Gansemer-Topf et al., 2007).
Further, these students face these challenges in the absence of the extensive network that supports first-year students. Post hoc reflection on comments from students in this study suggests that these observations were true specifically for students in the sciences (unpublished data).

According to the National Survey of Sophomore-Year Initiatives, about $50 \%$ of 4 -year colleges and universities have instituted initiatives specifically to address issues facing sophomores (Young et al., 2015). Despite this, the second year on most campuses has the fewest high-impact practices, particularly compared with the first year; thus, sophomores still receive the least attention of any class year (Young et al., 2015). An earlier iteration of the survey showed that, at campuses where there are programs in place, programs are often directed by student affairs professionals and only $\sim 20 \%$ are curricular, including credit-bearing courses and/or learning communities (Tobolowsky and Cox, 2007b). Programs and links to sophomore-specific programs can be found at http:// sc.edu/fye/resources/soph/research_publications.html.

\section{Institutional Context}

Grinnell College is a highly selective liberal arts college that is need-blind in admissions for domestic students and meets the full demonstrated need of admitted students. About $25 \%$ of Grinnell students are domestic SOC, 17\% are FG (neither parent having a college education), 24\% are Pell eligible, and 15\% are international. More than a third of Grinnell students graduate with science or math majors, and Grinnell ranks in the top few institutions as the baccalaureate source of students who earn PhDs in STEM areas. The college has a long-standing commitment to widening access to the sciences, largely through the Grinnell Science Project, a coordinated set of activities focused on introductory students. Coordination of programming is facilitated by all of the science departments (biology, chemistry, computer science, mathematics and statistics, physics, and psychology) being housed in the same building, the Noyce Science Center.

The Grinnell Science Project is a program focused on supporting inclusive excellence for first-year students (http://serc .carleton.edu/liberalarts/capstones/grinnell/persistence.html; www.grinnell.edu/academics/divisions/science/gsp). The project was launched when it was found that students-particularly SOC, women, and FG college students-were entering Grinnell College with an avowed interest in pursuing degrees in the sciences but abandoning their academic goals when they failed to do well in introductory science courses. In collaboration with student life administrators, Science Division faculty developed a program aimed at addressing three barriers to success in the sciences experienced by students we identified as members of groups that are underrepresented in the sciences: 1) unsuccessful acclimation to college life; 2) learning styles that do not respond to traditional pedagogy; and 3) a lack of mentors. The resulting program has three components to create an inclusive community of science for faculty and students alike: a weeklong preorientation program; an ongoing program of curricular and pedagogical reform emphasizing engaged and inquiry-driven learning; and a range of measures, including strong mentoring. The result is a web of mentoring; its success is a combination of activities and support, because the issues it addresses have no one solution. 
While maintaining Grinnell's traditional academic rigor, we have observed dramatic changes in the demographics of the students graduating with science and math majors since the Grinnell Science Project has been fully implemented. The representation of racial and ethnic groups in science and math majors is now roughly reflective of the overall student body. There has been an increase in each of the number of Hispanic and African-American students who graduate with science and math majors from an average of five per year to 14 per year. Half of science major graduates are now women. The number of woman graduates in physical and computational science areas (areas in which there was the most underrepresentation) has increased from about 11 to 37 per year. The effectiveness of this program was recognized in 2011 by a Presidential Award for Science, Engineering, and Mathematics Mentoring for efforts that enhance the participation and retention of individuals (including persons with disabilities, women, and minorities) who might not otherwise have considered or had access to opportunities in STEM (http://paesmem.net).

\section{Rationale for the Design of Interventions to Support Persistence of Second-Year Science Students}

Program development to support inclusive success of second-year science students was informed by the observations about experiences of second-year students described earlier and our experience of the effective comprehensive approach embraced by the Grinnell Science Project.

The efforts of the Grinnell Science Project are aligned with the whole-student model, tending to students' emotional, cultural, and resource needs along with academic needs (Jolly et al., 2004; Gross et al., 2015). Because it is reasonable to assume that some sophomores may give up on their intended majors due to a belief system that they do not have the capability to do the work or that they simply do not belong, efforts were made to address students' sense of social belonging (Walton and Cohen, 2007) and promote a sense of self-efficacy, including adoption of a growth mind-set (Dweck, 2006). The resulting program elements to support second-year science students are listed in the following sections.

Second-Year Science Student Retreat. A 1-day retreat was designed to prepare students for academic success in the second year and address decisions such as declaring their majors; selecting and effectively working with their academic advisors; identifying and taking advantage of campus resources such as the career center and learning labs; seeking off-campus study opportunities; and identifying activities to support career paths, such research opportunities, while building a sense of community and sense of belonging in the sciences. Data about the experience of second-year students from publications such as Gansemer-Topf et al. (2007) and a survey that participants and nonattendees in their cohort of students took at the beginning of the year reflecting attitudes, sense of belonging, and community were featured. Staff and faculty members, alumni, and upper-level students interacted with participants in several ways throughout the day, offering multiple opportunities to share personal experiences about the practice and culture of science on campus, pathways to becoming scientists, and what a life of science-related work entails. Each year, an average of 85 second-year science students attended the retreat out of 240 students invited; a schedule for the retreat appears in the Supplemental Material.

Faculty Development. Increased opportunities for activities contributing to a supportive community for faculty development, as recommended by Schreiner (2010) to support second-year students, were made available. Workshops and lunch meetings provided opportunities for small groups of faculty, sometimes with outside experts, to discuss experiences and readings related to specific topics known to affect inclusion and persistence in the sciences. Some topics addressed included implicit bias, metacognition, active learning (with Kimberly Tanner), and group work (with Karl Smith). Biology 251 (Molecules, Cells, and Organisms) and Chemistry 221 (Organic Chemistry) instructors worked to better coordinate their courses, since many students are coenrolled and find this combination challenging. Instructors attended one another's courses and developed and implemented teaching materials such as video clips and common quiz questions to reinforce students' understanding and ability to apply concepts from both disciplines (Sieck, 2015). Greater awareness of the timing of topics in each course along with improved explicit notation to students of how the content was related in the two courses facilitated learning in both courses.

Pedagogical Reform. Integrating engaged-learning and research experiences, especially those activities that increase students' responsibility for their own learning, has been called for in addressing challenges facing second-year students (Evenbeck and Hamilton, 2009). Support was provided for pedagogical reform in individual 200-level (intermediate-level) courses throughout science departments, including biology, chemistry, computer science, mathematics and statistics, and physics. Reform efforts have focused on increasing levels of student engagement through active pedagogies and inquiry-based learning, including lab development (Allen and Tanner, 2005; Freeman et al., 2014). For example, modules have been introduced into several 200-level science courses to provide more opportunities to give students more direct experience with common professional practices such as solving applied problems in teams, working on a community service-based project, designing an experiment, or analyzing data. To help students with the transition into the first semester of their second year, professors for the 200-level biology and chemistry courses invited students to join a Facebook group page with periodic posts of short review assignments during the late summer. About $75 \%$ of the invited students signed up for the group. Other changes have included faculty expressing an understanding of challenges in student development. Exercises such as asking students to make short notes at the ends of class noting points of confusion or to reflect on (and often share with the whole class) what strategies helped in studying for the last exam or coordinating group work on a project have also been implemented.

Science Learning Center. A new position staffed by a recent Grinnell graduate was added to increase the capacity of the Science Learning Center to provide mentoring, tutoring, and drop-in assistance for students, especially increasing support for students studying Organic Chemistry. 
Increased Research and Mentoring Opportunities. Funding for summer research opportunities and off-campus student presentations was augmented, and new funding was made available to provide employment opportunities for second-year students from targeted groups, including women in the physical sciences, SOC, and FG students. In the first 3 years of the program, more than 40 students participated in the student employment program. Opportunities were made available for students to attend conferences designed to provide students with a sense of belonging to a scientific community and to encourage and provide support for students from groups traditionally underrepresented in the sciences to pursue careers and advanced training in STEM. These conferences included meetings of the Society for the Advancement of Chicanos and Native Americans, the Annual Biomedical Research Conference for Minority Students, and the Grace Hopper Celebration of Women in Computing.

Assessment. Just as data disaggregated by social group categories informed the development and implementation of the Grinnell Science Project, we examined success and persistence of second-year students through transcript analysis and retention data for students who registered for 200-level science courses. To better understand the experiences and mind-set of students at the very beginning of their second year, we assembled a survey from existing resources to capture measures of students' attitudes and interests, community, and identity (Lopatto, 2010; Renninger and Schofield, 2014; Gross et al., 2015). These data informed subsequent focus groups and follow-up interviews as another mechanism to evaluate the impact of interventions. Data also informed programming, and survey responses were reflected back to students in the form of posters used at the second-year retreat and displayed in the science building.

\section{METHODS}

We used a mixed-methods approach in which we sought to characterize the perceptions of second-year students and to examine success and persistence of second-year students through transcript analysis and tracking retention of students who registered for 200-level science courses. A 200-level course is an intermediate course that assumes the student has completed at least one introductory prerequisite course. We gathered student perceptions through a systematic inquiry that aligned with key checkpoints in the second-year experience. First, to better understand the experiences and mind-sets of students at the very beginning of their second year, we surveyed students before and immediately following the second-year retreat. These data informed focus groups held at the beginning of students' fourth semester and follow-up interviews conducted after the declaration of an intended major at the end of the second year. These qualitative approaches served as another mechanism to evaluate the impact of interventions.

\section{Second-Year Surveys}

At the beginning of the Fall term for three consecutive years (2013-2015), second-year math and science students were invited to a Fall all-day retreat via an email sent from Grinnell College science faculty. As part of the invitation to the retreat, students were asked to complete a brief online survey. We assembled the survey from existing valid and reliable instruments, adopting full scales of question items intended to capture a sense of students' attitudes, communities, and identities (Lopatto, 2010; Renninger and Schofield, 2014; Gross et al., 2015). Nonresponders to the survey received a second and/or third invitation. During the second-year retreat, the data from the survey were shared on posters with participating students. In year 1 , the survey was administered online through the Science Education Resource Center (SERC) website at Carleton College. Subsequently, it was administered through Grinnell College's Office of Analytic Support and Institutional Research. The survey items are shown in the Supplemental Material. Following the second-year retreat, an additional end-of-event survey was administered to retreat participants to gather formative feedback from students specific to the retreat.

\section{Focus Groups}

In the Winter of 2014, a focus group study was conducted. The purpose of this qualitative study was to characterize the following:

- How the current college processes and mechanisms for supporting students declaring a major support or inhibit students' persistence, particularly in STEM;

- What communities and relationships within the college inform the student experience and affect students' aspirations and academic expectations; and

- How classroom environments, dynamics, and perceptions about courses influence students' persistence in a given major.

\section{The eight focus groups included}

- Students in their second year who had science or math aspirations. Participants included both preretreat survey respondents and those who had not completed the preretreat survey.

- Students who had declared a major in science or mathematics (third- or fourth-year students).

Effort was made for student groups to include a broad representation of students by how they self-identified to the college, including gender, racial categorization, and FG status. The groups included 47 second-year students and one focus group of 14 third- and fourth-year students. Focus groups were conducted on campus, and each focus group was audio-recorded and subsequently transcribed. The verbatim transcripts were coded in NVivo by E.I. using a grounded theory approach. As part of the systematic inquiry process, a sample of the focus groups was coded by another SERC evaluator. Coding books were compared, and the qualitative analysis was revised accordingly.

\section{Interviews}

As the closing checkpoint in the 2013-2014 academic year, 14 second-year students were interviewed by telephone in their final week of class (after they had completed preregistration/declared a major). These interviews explored the perceived challenges and also provide structured feedback loops for some of the pilot strategies used to support second-year students. Effort was made to include students who 
had not participated in the focus groups or who responded less favorably on the September survey. For these interviews, 48 students who had not participated in a focus group were invited, and 11 chose to participate in interviews. From the focus groups, 10 students were invited for interviews, and three students participated.

\section{Analysis of Success of Second-Year Students in 200-Level Science Classes}

Data Collection. All data were extracted from Grinnell's student information system. When referring to rates of success, the enrollment $N$ is 5153. Unless otherwise noted, course enrollments, not students, is the level of analysis.

Variables Used in Analyses. The grouping variables for the analysis were coded as SOC, FG, and intervention (pre versus post).

Included in the SOC group were students whose federal ethnicity definition was African American, Asian, Latino/a, Native American, or multiethnic. Students not included in this group constitute the group "other." FG students were defined as students who were the first members of their families to enroll in an institution of higher education. For some analyses, the student ethnicity variable was crossed with the FG variable to produce subgroups: FG SOC, non-FG SOC, FG other, and non-FG other. The intervention variable was created to include data from the academic years 2007-2010 (preintervention) and 2012-2014 (postintervention). Data from 2011, a transition year, were excluded from the analysis. All the students included in the study were second-year students at the time of their enrollments.

The dependent variable for the analysis was "success." Success was defined as a student remaining in a course between registration and the end of the course and receiving a grade of "C" or better. The grade of "C" or better was chosen because one other passing grade, "D," does not qualify the course as counting toward the student's major in that field or as a prerequisite for a subsequent course. Success, per se, is a dichotomous variable (one succeeds or not); however, our students enroll in multiple science courses. With enrollments as the level of analysis, it was possible to calculate a success rate for the student data. For example, if a student enrolled in three science classes and succeeded in two, his or her success rate was 0.67 .
Data Analysis. The initial analysis included the domain of all 200-level (intermediate) courses in the Science Division of the college. A second analysis was performed for two gateway courses taken by a large number of second-year students, Biology 251 (Molecules, Cells, and Organisms) and Chemistry 221 (Organic Chemistry). Our principal interest was in comparing success rates preintervention to postintervention. We hypothesized that the program of interventions would increase the success rates. We were also interested in differential results for the SOC, FG, and other groups and their combinations. Our approach was to perform analysis of variance (ANOVA) followed by post hoc pairwise comparisons, including Tamhane's comparison, a conservative $t$ test. Data analysis was performed using SPSS, version 22.

\section{RESULTS}

\section{Student Success in 200-Level Courses}

At Grinnell College, 200-level courses are intermediate between 100-level introductory courses and 300-level advanced courses. Typically, science and mathematics majors take at least two 200-level courses in their major field during their second-year, and most 200-level courses require at least one 100-level prerequisite. To fulfill prerequisites, students must earn a grade of "C" or better in the designated prerequisite course. To assess successful completion of 200-level courses, we examined the percentage of second-year students who registered in 200-level courses and then completed the courses receiving a grade of "C" or higher. Data were extracted from the Grinnell College student information system. Students were identified as domestic SOC, FG, or neither. If students were both SOC and FG, they were counted in both categories. We looked at the 3 years before this project started (2007-2010) and after initiation of the project (2012-2015). Data are summarized in Table 1. Before this project, the rate of success of second-year students in a 200-level science or mathematics course was significantly lower for SOC and FG students than for students who are not in these groups. We noted that, if students who are both FG and SOC are removed from either group, the percentages of students succeeding increased substantially, indicating that SOC who are FG are at higher risk than those SOC who are not FG or those who are FG but not SOC.

For the 3 years during programming, the overall rates of successfully completing the courses did not change materially. However, in the Biology 251 (Molecules, Cells, and Organisms)

TABLE 1. Percent of registered students completing 200-level courses with grades of " $C$ " or higher

\begin{tabular}{|c|c|c|c|c|c|c|}
\hline & \multicolumn{3}{|c|}{$2007-2010^{a}$} & \multicolumn{3}{|c|}{$2012-2015^{b}$} \\
\hline & SOC & FG & All other students & SOC & FG & All other students \\
\hline Biology 251 & $75 \%$ c & $70 \%{ }^{\mathrm{d}}$ & $88 \%$ & $89 \%{ }^{c}$ & $87 \% \%^{\mathrm{d}}$ & $88 \%$ \\
\hline Chemistry 221 & $76 \%{ }^{\mathrm{e}}$ & $76 \%{ }^{\mathrm{f}}$ & $86 \%$ & $83 \% \mathrm{e}^{\mathrm{e}}$ & $84 \%^{\mathrm{f}}$ & $87 \%$ \\
\hline All other 200 -level courses & $76 \%{ }^{g 1}$ & $80 \%{ }^{g 1}$ & $87 \%{ }^{g 2}$ & $79 \%{ }^{\mathrm{h} 1}$ & $78 \%{ }^{\mathrm{h} 1}$ & $88 \%$ h2 \\
\hline
\end{tabular}

aThese proportions are calculated from 2591 enrollments from Fall 2007 to Spring 2010. This includes 390 SOC and 215 FG enrollments and 149 enrollments that were both SOC and FG.

${ }^{b}$ These proportions are calculated from 2562 enrollments taking these courses from Fall 2012 to Spring 2015. This includes 424 SOC and 223 FG enrollments and 234 enrollments that were both SOC and FG. The enrollments that were both SOC and FG are counted in both SOC and FG success rates, making the SOC and FG as presented in the table nonorthogonal groups.

${ }^{\mathrm{c}-\mathrm{f}}$ Groups superscripted with similar letters were found to have significantly improved success rates in the postintervention period.

g,h The g1/h1 superscripted groups were found to have significantly lower rates of success in both the pre- and postintervention periods compared with g2 and h2 (Supplemental Table S2). 


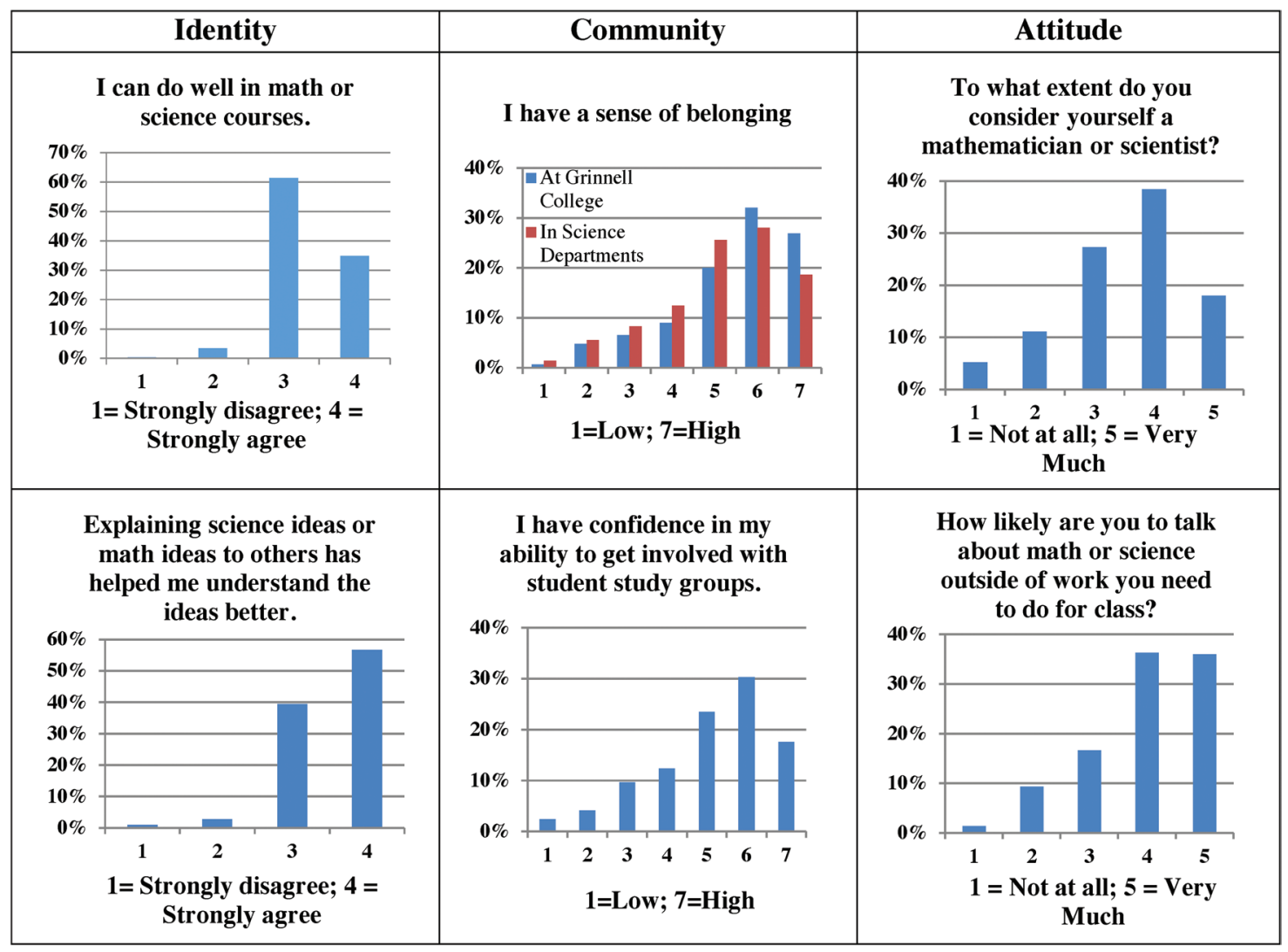

FIGURE 1. Sample survey results graph (combined for the 3 years of administration) for six of the 33 questions, two in each category. Distribution of responses on the Likert scale as indicated on the legend.

and Chemistry 221 (Organic Chemistry) courses, in which faculty implemented reforms as part of this project, the rate of successfully completing the courses increased dramatically and significantly (using one-way ANOVA and $t$ tests; see Supplemental Tables S1, S2, S3, and S4) for SOC and FG students, approaching those for all other students. More specifically, the successful completion rate of Biology 251 for SOC and FG students increased from 73 to $88 \%$ and the Chemistry 221 successful completion rate increased from 76 to $83 \%$ for SOC and FG students (Table 1).

\section{Second-Year Survey Reflecting Student Attitudes about Science}

The invitation to complete a survey of attitudes about science was sent to second-year students enrolled in at least one 200level science course each of three years (2013-2015) along with the invitation to participate in the second-year retreat. The survey was intended to assess the current culture of second-year science students at the college. It was not an assessment of program outcomes. However, the results of selected items were posted at the retreat and in the science building to provide opportunities for students to discover consensus information regarding their feelings about science and math. The frequency with which students read this information was not measured. The response rates for the 3 years of survey administration are shown in Supplemental Table S5, and some sample responses for questions in each of the categories of attitudes about science, sense of community, and identity as a scientist are presented in Figure 1.

Gender, ethnicity, and FG status were distributed in the survey responses in rough proportion to the student population. Following data collection, the results for 2 years in which data were available concerning drop rates were merged with the survey results.

Each section of the survey was analyzed for interitem consistency. Cronbach's alpha was calculated for each section. The first 11 attitude items yielded alpha statistics ranging from 0.84 to 0.88 over 3 years. The second 11 community items yielded alpha statistics ranging from 0.82 to 0.86 . The third 11 identity items, after some negatively phrased items were reverse scored, yielded alpha statistics ranging from 0.65 to 0.77 . The items for each section were then summed, yielding three scores for each student respondent.

As shown in Figure 2, student scores were generally high, indicating a positive perception of science and the science program at the college. In these survey results, there were no statistically significant differences between demographic groups or across years or between students who did or did not succeed in their 200-level courses during these years of programming.

In addition to being reflected back to students during programming, survey results were used to structure the content of 


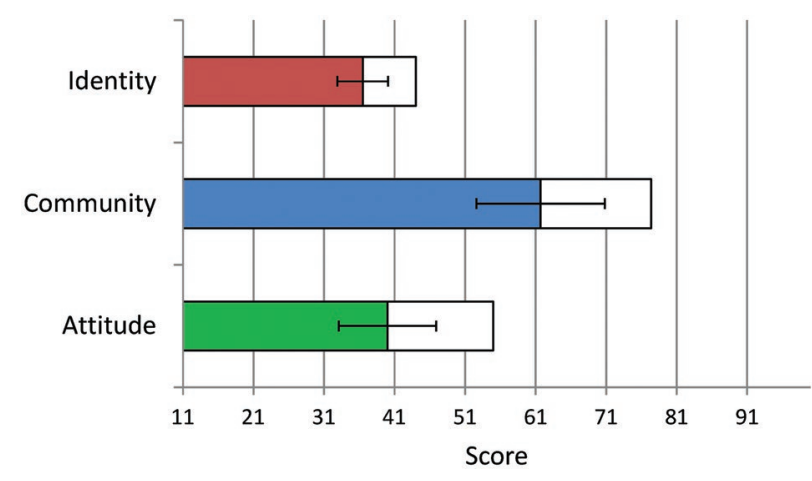

FIGURE 2. Three years of survey data summarized by scale. The figure shows the mean responses for $\sim 280$ second-year students (colored bar), the theoretical maximum of each scale (white bar), and the SD of each scale (error bars).

the focus groups and interviews that are the qualitative part of this work.

\section{Qualitative Analysis of Experiences of Second-Year Students}

Focus groups conducted during the semester after the survey administration reveal a major theme: second-year students perceive a culture of openness and support. Talking or working one-on-one with professors was the strategy mentioned most frequently by students in focus groups and interviews. Approaching faculty was perceived as easier in the second year compared with the first year. Students from both the focus groups and Spring interviews appreciated the culture of support from professors in regard to talking with students outside class about topics such as courses they should take, majors, and careers. Students commented on the willingness of faculty to talk to students outside class (six of eight focus groups) and identified peer mentors, academic advisors, and the second-year retreat as other critical components of the supportive programming.

For example, when asked during a focus group what things have been particularly helpful at Grinnell in helping students think about being in the sciences or math, one student interested in computer science responded, "I've had really good experiences talking to ... computer science faculty, because they're so available ... there's talks every Thursday about various computer science topics, and they're there. And before the talks, we all hang out,... And on Fridays, we all eat lunch together and discuss articles ... when I realized that I didn't know one of the computer science professors and probably wouldn't take a class from her, I signed up to just go on a walk with her one day, and we just talked about computer science things."

All students in focus groups described relationships that were supportive and critical to their learning. In seven of eight focus groups, students described the importance of peer academic mentors as a resource for learning about and supporting different STEM trajectories. A key aspect of this relationship was the approachability of peer mentors, with five of the eight focus groups describing ways they found peer mentors more accessible than faculty. When students were asked what had been helpful in thinking about their goals and aspirations, peer mentors were a frequent response (six of eight focus groups). As one student described it, "[peer] mentors in my bio 150 class and also my chemistry classes, they're really helpful in kind of guiding you on a path of what you want to do with your future. They're really excited about what they do." While students highly valued peer mentorship, they also noted an area for improvement. A few students in focus groups (two of eight groups) and one interviewee reported that the college lacks multicultural mentors. While some mentorship is available, students perceive that the college does not reach out to students enough or that the work in this area is not very well organized.

Students view formal academic advising as another critical support to their second-year experience. In the majority of focus groups (five of eight), students attributed their balanced liberal arts set of courses to strong guidance from their advisor. When students had a non-science advisor, they had more difficulty knowing what science courses to schedule (six of eight focus groups). However, students appreciated that their nonscience advisor encouraged them to take a broad range of classes and seek out others in the science community (five of eight focus groups).

The sophomore retreat was appreciated by students as another source of emotional support and validation for the stresses of the second-year experience (four of eight focus groups). These data aligned with student evaluations of the second-year retreat, in which more than $90 \%$ of students reported that they would recommend participating in the second-year retreat to other students, and $87 \%$ reported that the retreat enhanced their sense of belonging in the sciences at Grinnell. Students expressed appreciation for department-sponsored events that help them learn about the field, what it is like to work in the field, and pathways to enter the field. Other informal events allowing for interactions with faculty were valued, and campus offices were identified as being helpful in different ways.

Students across all focus groups commented on the Noyce Science Center as a place to seek and find help. They commented on the ready-made places to meet for group work, informal spaces for study, and places designated to meet other science students. Computer labs were valued as a space to seek help from peers and more senior students at all hours of the day, and female students particularly appreciated the gender-neutral ambience. Even students who were not as certain that they would declare a STEM major identified the Noyce spaces as a means to keep connected to their science interests. As one student responded in a focus group, "And so I think the revelation that you can still do things that are science related, you can still ... hang out in Noyce, you can still take science classes, but you don't have to be a science major was really important to me."

Pedagogical features mentioned included an appreciation of small class sizes, well-put-together syllabi, and clear expectations. Students also reported liking classes to be a blend of lecture, group work, discussion, and demonstrations that help tie together theory and application.

Students in several of the focus groups mentioned that labs were helpful for understanding what a science career would be like in reality. Students liked the use of examples from lab in class and vice versa in order to facilitate transfer of knowledge. 
Although the focus groups and interviews characterized the value of the different supports, students also described ongoing challenges particularly connected to the second-year experience. Students observed the workload is more difficult in the second year, and the challenge of taking Biology 251 (Molecules, Cells, and Organisms) and Chemistry 221 (Organic Chemistry) at the same time was mentioned. Students in several of the focus groups commented that it is more difficult to join different clubs or groups as a second-year student, because new recruitment efforts are aimed at first-year students.

Group work was a challenge commented on by students from all focus groups and several Spring interviewees (four of 14). They viewed as challenges: working with students who are less engaged, assignments that are not as naturally team oriented, or just dealing with scheduling conflicts to complete the work together. Some students reported feeling intimidated talking to professors to seek help with group-work issues, such as domineering students or students who are underprepared. Several students in the Spring interviews commented that they were more confident approaching faculty with group-work issues in their second year. One Spring interviewee reflected back on the group-work experience and shared, "The further I've gotten into the course work for certain majors, it seems group work is a lot easier to, you know, really do well and enjoy, because most of the students kind of share your aptitude and enjoy the course work." Another student from the focus groups characterized group work as a way to engage in the science community, noting that "with my $\mathrm{O}$ chem class, we didn't have, we weren't required to work in groups for our problem sets. But the problem sets were designed that if you worked on it by yourself you were kind of in a bad situation, making yourself just work way too hard. So the fact that the problem sets were so hard was good in that sense and really fostered a good class community. We all bonded over how hard everything was."

While group work was identified as a challenge by students, it was also valued as a science skill and viewed as an opportunity to meet other students in the sciences. Students commented on strategies that made group work easier, such as choosing your own groups based on schedules. One strategy used by a computer science faculty member was to have students complete a learning styles preference survey and have a 15-minute meeting with the professor at the beginning of the course to provide better paired programming matches. Students also valued situations wherein the assignment itself was made easier by group collaboration, rather than feeling forced or requiring more effort and less value. Another set of students remarked on professors who have clear standards for group work that make it easier to navigate the relationship and clarify what each student must contribute. Students from both focus groups and interviews viewed the Science Learning Center as an essential meeting place for group work.

Students also commented that, while they would not have chosen on their own to do group work, having been exposed to the experience, they now view it as essential. This realization was described by one student who shared, "I don't think I would have sought it [group work] out had I not been exposed to it like the first or second year. Like I didn't really do group work my first year, and then because I needed it so much last semester, now I do."

\section{DISCUSSION}

This project addresses the challenges particular to second-year students that may impact persistence in STEM-related fields. We found that second-year SOC and FG students who registered for 200-level science courses did not successfully complete those courses at the same rates as students not in those categories. Of particular concern were Biology 251 (Molecules, Cells, and Organisms) and Chemistry 221 (Organic Chemistry), intermediate-level biology and chemistry courses that serve as gateway courses to pre-health students, biology majors, chemistry majors, and biological chemistry majors. During the period of this programming dedicated to increasing students' engagement and sense of belonging in the sciences, 2012-2015, the gap between rates of success of SOC and FG students in these gateway courses versus other students narrowed significantly (Table 1). This positive effect was not observed for other courses. This could be due to a number of factors, including the fact that faculty development efforts and additional support for the Science Learning Center was targeted toward Biology 251 (Molecules, Cells, and Organisms) and Chemistry 221 (Organic Chemistry). Those two courses enroll $\sim 120$ students per year, more than a quarter of the second-year class of students at the college, so these courses are significant as student success measures, not just for biology and chemistry, but for the college as whole.

We hypothesized that students who did not succeed in these courses may have had differences in attitude, sense of identity as scientists, or feeling like part of the community of scientists (Seymour et al., 2004; Hunter et al., 2007). Results of a survey designed to examine these factors did not show significant differences between students who did or did not succeed in intermediate-level science courses. In fact, the survey data indicate students rated these factors positively (see Figures 1 and 2).

This survey was a brief, closed-ended instrument designed to provide data quickly. In addition to informing follow-up qualitative studies of students' second-year experiences, the information from the survey was used to inform programming and to reflect back to students. Results such as those depicted in Figure 1 were made into posters that were displayed at the second-year retreat and then in the Noyce Science Center. In addition to survey responses, posters included additional questions designed to provoke reflection by students about how they fit in and what their styles of learning might be and about resources and techniques available to them to promote their success. This information, combined with related discussions at the second-year retreat, could possibly enhance students' sense of belonging, encourage them to think more in a growth mind-set (that there are tactics they may employ to be more successful; Dweck, 2006), and minimize effects of misperception of how easy peers may find the challenges of studying science, analogous to social norming work to mitigate effects of misperceptions of peer behavior on alcohol consumption (Berkowitz, 2005). We note, however, that the information presented in the posters generally showed positive attitudes. It remains for future research to discern whether neutral or negative attitudes presented in posters would have the effect of improving student behavior.

The most striking theme of the qualitative study was that students felt well supported. These focus groups and interviews happened in the middle and toward the end of students' second years, respectively. This finding could reflect maturation during the second year, although the survey responses from the very 
beginning of the second year reflected positively on students' attitudes, sense of belonging, and sense of identity as scientists (Figure 2). The elements students reported as contributing to this positive view align with identified best practices for inclusive excellence (for a review, see Graham et al., 2013), including peer mentoring, a sense of community, close interactions with faculty (including academic advising), and engaged pedagogical practices. Barriers and challenges aligned with the findings reported in Gansemer-Topf et al. (2007) include managing a more demanding workload and needing support for planning career paths. Improving self-knowledge about estimating workload, improving time management, and using resources for academic support may be summarized as improvements in metacognition, commonly defined as "thinking about thinking" and including knowledge about one's abilities and task demands (National Research Council, 2000).

It must be noted that, despite the findings of the qualitative work that indicate positive attitudes, a good sense of identity as a scientist, and a strong sense of community by students, the rates of successful completion of 200-level courses by SOC and FG students remain lower than the overall success rate (Table 1). Future investigations may include gauging what students know about tactics for successful learning in science courses. One promising direction is the Student Engagement with Academic Support survey (SEAS; http://apps.carleton .edu/curricular/support/research/SEAS) created by Andrea Nixon of Carleton College (Nixon, 2011)

Our faculty development efforts led faculty to make changes as well. For instance, through learning more about metacognition, faculty members have implemented exercises to assist students to develop better metacognitive reflection. In addition, some faculty members have become more explicit in talking to students about some topics or concepts being very challenging, so that, when they feel "this is hard," it is because it is "hard," not that they cannot do it. In another area, a workshop and other discussions about cooperative learning helped faculty members to better structure group activities and to be explicit in their goals that all group members respect their peers and recognize the different perspectives and talents that each member brings to the group. In addition, we have emphasized the importance of being able to work effectively in diverse groups is an important life and professional skill.

Based on our success with the Grinnell Science Project, the second-year programming was designed as a web of support (Jolly et al., 2004; Gross et al., 2015), focusing on institutional change as opposed to "fixing" the students. Origins of both programs were similar. Both began with faculty observations related to experiences of students from some groups recognized nationally as underrepresented in the sciences. Analysis of data supported those hunches, programming was developed, and funding was obtained. Funding from the Howard Hughes Medical Institute for the second-year project was especially valuable, since the award is made to the institution, fostering involvement of groups of faculty, staff, and administrators.

Many of our interventions require modest effort and cost. For instance, the survey can be implemented with the most basic features of survey software, and since the responses are all on a Likert scale, descriptive statistics and display are straightforward. The second-year retreat requires more effort to organize but can be replicated in subsequent years with far less effort. Activities such as informal departmental or course-based lunches in the dining hall are inexpensive and easy to implement. They help faculty to understand the issues students are facing and to think about how to best respond to them, and they help students feel they are important and belong in the scientific community. These inexpensive activities may well serve as the basis for attracting grant or internal funding to launch more costly activities.

When evaluating a comprehensive program, it is difficult to partition the effects of distinct activities related to student programming, faculty development, and organizational change, because they may not be orthogonal variables that have an additive effect on student learning, sense of community, and retention. Rather, the interventions described in this paper may interact with one another in unknown ways. We believe that perhaps the most significant change in student learning that occurred was not due to any particular activity or policy change, but to the holistic effect stemming from faculty, student, and staff awareness being raised about the common issues facing second-year science students. Faculty appreciate how important their passion and belief in the abilities of their students to succeed are (as described by Schreiner, 2010). Faculty might note to their intermediate-level students that the level of conceptual difficulty has increased and the course will be more challenging for all students but that students are capable of succeeding in the class and have access to academic support resources that will help them do so. Faculty can help students realize that they are in a supportive environment that, rather than "weeding out" students, encourages them to excel, even while they deal with competing demands on their time and increasing content complexity. Faculty can explicitly recognize some of the challenges present in group work, in particular in dealing with diverse (along multiple dimensions) groups of students, which can assist students in learning to recognize and respect the perspectives and strengths that different students bring. Faculty can explicitly note that such group work not only contributes to learning content but also to skills that are critical to becoming leaders in society, whether is science or in other personal, civic, and professional realms (Association of American Colleges and Universities, 2008). Persistence is a tremendously complicated issue that is affected by students' academic preparation but also by noncognitive aspects such as feelings of belonging and self-efficacy.

Our programs to support inclusive excellence of introductory- and intermediate-level undergraduates demonstrate the value of having small institutions become situated to incubate innovation in science education. We have a record of improving student learning and enabling student access to professional development (Cech, 1999). While the size of our institution does not permit direct research with scaling-up innovations, our vision is to continue to test interventions that improve science education that will be shared with the broader STEM community. We are interested in demonstrating what can happen and leave it to other institutions to see how well the interventions described here replicate in other environments.

\section{ACKNOWLEDGMENTS}

This program was supported in part by a grant to Grinnell College from the Howard Hughes Medical Institute through the 
Precollege and Undergraduate Science Education Program. We thank the Grinnell College students who participated in this study and the faculty and staff who contributed to development and implementation of inclusive programming for second-year students. We thank Carlie VanWilligen, director of Institutional Research at Grinnell College, for assistance with survey administration and data acquisition and Susan Ferrari, director of Corporate, Foundation, and Government Relations at Grinnell, for assistance with editing the manuscript.

\section{REFERENCES}

Association of American Colleges and Universities (2008). College Learning for the New Global Century: Executive Summary (with Employers' Views on Learning Outcomes and Assessment Approaches), Washington, DC.

Allen D, Tanner K (2005). Infusing active learning into the large-enrollment biology class: seven strategies, from the simple to the complex. Cell Biol Educ 4, 262-268.

Berkowitz AD (2005). An overview of the social norms approach. In: Changing the Culture of College Drinking: A Socially Situated Health Communication Campaign, ed. L Lederman and LP Stewart, New York: Hampton.

Cech TR (1999). Science at liberal arts colleges: a better education? Daedalus $128,195-216$.

Dweck CS (2006). Mindset: The New Psychology of Success, New York: Random House.

Evenbeck SE, Hamilton SJ (2009). Curricular approaches for the intellectual development of second-year students. In: Helping Sophomores Succeed: Understanding and Improving the Second-Year Experience, ed. MS Hunter, BF Tobolowsky, JN Gardner, SE Evenbeck, JA Pattengale, MA Schaller, and LA Schreiner, San Francisco: Jossey-Bass

Freedman MB (1956). The passage through college. J Soc Issues 12, 13-27.

Freeman S, Eddy SL, McDonough M, Smith MK, Okoroafor N, Jordt $H$ Wenderoth MP (2014). Active learning increases student performance in science, engineering, and mathematics. Proc Natl Acad Sci USA 111, 8410-8415

Gansemer-Topf AM, Stern J, Benjamin M (2007). Examining the experiences of second-year students at a private liberal arts college. In: Shedding Light on Sophomores: An Exploration of the Second College Year (Monograph No. 47), ed. BF Tobolowsky and BE Cox, Columbia: University of South Carolina, National Resource Center for the First-Year Experience and Students in Transition, 31-48.

Gardner PD (2000). From drift to engagement: finding purpose and making career connections in the sophomore year. In: Visible Solutions for Invisible Students: Helping Sophomores Succeed (Monograph No. 31), ed. LA Schreiner and J Pattengale, Columbia: University of South Carolina, National Resource Center for the First-Year Experience and Students in Transition, 67-77.

Graham MJ, Frederick J, Byars-Winston A, Hunter AB, Handelsman J (2013). Increasing persistence of college students in STEM. Science 341, 14551456.

Gross D, Iverson E, Willett G, Manduca C (2015). Broadening access to science with support for the whole student in a residential liberal arts college environment. J Coll Sci Teach 44, 99-107.

Hunter AB, Laursen SL, Seymour E (2007). Becoming a scientist: the role of undergraduate research in students' cognitive, personal, and professional development. Sci Educ 91, 36-74.

Hunter MS, Tobolowsky BF, Gardner JN, Evenbeck SE, Pattengale JA, Schaller MA, Schreiner LA (eds.) (2010). Helping Sophomores Succeed:
Understanding and Improving the Second-Year Experience, San Francisco: Jossey-Bass.

Jolly EJ, Campbell PB, Perlman L (2004). Engagement, Capacity, and Continuity: A Trilogy for Student Success, GE Foundation. www.campbell -kibler.com/trilogy.pdf (accessed 15 August 2016).

Kennedy K, Upcraft ML (2010). Keys to student success: a look at the literature. In: Helping Sophomores Succeed: Understanding and Improving the Second-Year Experience, ed. MS Hunter, BF Tobolowsky, JN Gardner, SE Evenbeck, JA Pattengale, MA Schaller, and LA Schreiner, San Francisco: Jossey-Bass, 30-42.

Lemons LJ, Richmond DR (1987). A developmental perspective of sophomore slump. NASPA J 24(3), 15-19.

Lopatto D (2010). Science in Solution, Tucson, AZ: Research Corporation for Science Advancement.

National Research Council (2000). How People Learn: Brain, Mind, Experience, and School, Washington, DC: National Academy Press.

Nixon A (2011). Student engagement with academic support (SEAS): focusing institutional efforts on student needs. Presented at EDUCAUSE Annual Conference, held October 18-21, 2011, in Philadelphia, PA.

Renninger KA, Schofield LS (2014). Assessing STEM interest as a developmental motivational variable. Poster presented as part of the structured poster session Current Approaches to Interest Measurement, KA Renninger and S Hidi, chairs, American Educational Research Association, held April 3-7, 2014, in Philadelphia, PA.

Schaller MA (2005). Wandering and wondering: traversing the uneven terrain of the second college year. About Campus 10(3), 17-24.

Schreiner LA (2010). The critical role of faculty and faculty development in sophomore success. In: Helping Sophomores Succeed: Understanding and Improving the Second-Year Experience, ed. MS Hunter, BF Tobolowsky, JN Gardner, SE Evenbeck, JA Pattengale, MA Schaller, and LA Schreiner, San Francisco: Jossey-Bass.

Schreiner LA, Pattengale J (eds.) (2000). Visible Solutions for Invisible Students: Helping Sophomores Succeed (Monograph No. 31), Columbia: University of South Carolina, National Resource Center for the First-Year Experience and Students in Transition.

Seymour E, Hunter A-B, Laursen SL, DeAntoni T (2004). Establishing the benefits of research experiences for undergraduates in the sciences: first findings from a three year study. Sci Educ 88, 493-534.

Sieck SR (2015, March 22-26). Building connections in biology and chemistry courses in the second-year curriculum (abstract 1807). In: American Chemical Society 249th Annual Meeting Program, Denver.

Tobolowsky BF, Cox EE (eds.) (2007a). Shedding Light on Sophomores: An Exploration of the Second College Year (Monograph No. 47), Columbia: University of South Carolina, National Resource Center for the First-Year Experience and Students in Transition.

Tobolowsky BF, Cox EE (2007b). Findings from the 2005 National Survey on Sophomore-Year Initiatives. In: Shedding Light on Sophomores: An Exploration of the Second College Year (Monograph No. 47), ed. BF Tobolowsky and EE Cox, Columbia: University of South Carolina, National Resource Center for the First-Year Experience and Students in Transition, $13-30$

Walton GM, Cohen GLA (2007). Question of belonging: race, social fit, and achievement. J Pers Soc Psychol 92, 82-96.

Wilder J (1993). The sophomore slump: a complex developmental period that contributes to attrition. Coll Stud Aff J 12(2), 18-27.

Young DG, Schreiner LA, Mclntosh EJ (2015). Investigating Sophomore Student Success: The National Survey of Sophomore-Year Initiatives and the Sophomore Experiences Survey, 2014 (Research Reports No. 6), Columbia: University of South Carolina, National Resource Center for the First-Year Experience and Students in Transition. 